\title{
Apparently changing patterns of inheritance in Alport's hereditary nephritis: Genetic heterogeneity versus altered diagnostic criteria
}

\author{
Sarah Helen Evans', Robert P. Erickson 1,2 , Robert Kelsch ${ }^{2}$ and John C. Peirce 3 \\ Departments of 1 Human Genetics and 2 Pediatrics, \\ University of Michigan School of Medicine, Ann Arbor, and \\ 3 Nephrology Department, St. Mary's Hospital, Grand Rapids, Michigan, U.S.A.
}

\begin{abstract}
With the use of more stringent diagnostic criteria, it has recently been shown that some large pedigrees of Alport's and non-Alport's hereditary nephritis fit sex-linked dominant inheritance (O'Neill et al. 1978). We have used similar diagnostic criteria and have studied a number of Michigan pedigrees in order to see if this hypothesis would be confirmed. We found one small pedigree which definitely shows male-to-male transmission, while one large pedigree is tentatively compatible with sex-linked dominant inheritance. Many of the other pedigrees suggested male-to-male transmission. This Michigan experience is compared to other published reports and found to be consistent, although a trend of fewer reports of male-to-male transmission is seen. We conclude that genetic heterogeneity of Alport's hereditary nephritis is likely.
\end{abstract}

Received 12 November, accepted for publication 6 December 1979

Key words: Alport's syndrome; dominant inheritance; genetic heterogeneity; nephritis; segregation ratios; $\mathrm{X}$-linkage.

Since its definition in the late 1920's (Alport 1927), Alport's syndrome, hereditary nephritis with sensorineural deafness, has been studied extensively, especially in the last 15 years. Many studies have been devoted to the determination of the mode of inheritance of Alport's syndrome, which does not seem to fit any traditional Mendelian pattern. Recently, O'Neill et al. (1978) considered Alport's disease to be a subset of a more encompassing disease, hereditary nephritis. Although their definition of hereditary nephritis includes several renal dis- eases previously considered to be distinct, they feel that revised definitions and methods for identifying affected persons are necessary. For their analysis of the inheritance pattern of hereditary nephritis, they have chosen two pedigrees. One, which shows classic Alport's syndrome, is an updated version of the Utah pedigree previously reported by Perkoff et al. (1951). O'Neill et al. (1978) have re-examined some of the patients whom the Perkoff group had examined and in several cases, notably those of affected males with either an affected 
father or son, the diagnosis has been changed from affected to unaffected. The result is that no case of male-to-male transmission of the disease now occurs in the pedigree. Because of these changes and additions, O'Neill and his associates have come to the conclusion that hereditary nephritis, including Alport's syndrome, is transmitted as a dominant, $\mathrm{X}$-linked gene. This conclusion implies that males who are affected will transmit the disease to all their daughters and none of their sons, and that affected females will transmit the disease to half of their offspring, daughters and sons alike.

We report here a family strongly indicative of male-to-male transmission, a new large pedigree of Alport's syndrome, and an analysis of segregation patterns in these, several other unpublished cases from the University of Michigan, and published cases from the literature.

\section{Material and Methods}

The medical records of patients with hematuria and/or renal insufficiency seen in the Pediatric Nephrology Department at the University of Michigan were reviewed to locate pedigrees of Alport's syndrome. A pedigree was considered acceptable if, and only if, at least one member in each of three generations, or at least two members of one generation and one member of another generation met one of the following sets of criteria: (1) hematuria and deafness, (2) gross or microscopic hematuria, (3) deafness alone in a female, or (4) renal biopsy findings compatible with Alport's syndrome. Deafness was required in at least one individual in the pedigree. Fourteen such pedigrees were discovered and the family members classified. We report one family here in detail because it strongly indicates male-to-male transmission.

One patient with hematuria and her mother, who displayed a slight sensorineural deafness, were seen at the University of Michigan Hospital and were discovered to be relatives of two patients who had been seen in the Nephrology Department of St. Mary's Hospital in Grand Rapids, Michigan since the early 1960's because of repeated episodes of gross hematuria. Research into the family histories of these relatives indicated hereditary nephritis (later proven to be Alport's syndrome by the occurrence of deafness in the family) as the probable cause of the hematuria. Further family research at that time uncovered many affected relatives, but the pedigree was left incomplete due to the fact that few family members were able to provide information about their relatives other than members of their nuclear families.

The pedigree was reinvestigated in the summer of 1978, at which time an effort was made to obtain information about all family members through personal contact with each, and through the investigation of medical records. A urine sample and blood pressure reading were obtained from each individual, except in the cases of menstruating women, children in diapers, and family members who refused to cooperate. Urine samples were checked with a Dip-Stick ${ }^{\circledR}$ within $15 \mathrm{~min}$ of voiding for proteinuria and hematuria. The refrigerated sediment was examined for red blood cells and red blood cell casts within $48 \mathrm{~h}$ of collection if the Dip-Stick $\odot$ test indicated hematuria. In light of the family history of Alport's syndrome, an individual with hematuria is considered to be affected.

\section{Results}

\section{University of Michigan Pedigrees}

One hundred and sixty-nine individuals in 14 pedigrees were classified as affected or unaffected according to the criteria enumerated above. The data are presented ac- 
Table 1

Classification of individuals in University of Michigan Alport's pedigrees by sex, disease state, and affected parent

\begin{tabular}{lcc}
$\begin{array}{l}\text { Affected } \\
\text { parent }\end{array}$ & $\begin{array}{c}\text { No. affected } \\
\text { sons/total sons }\end{array}$ & $\begin{array}{c}\text { No. affected } \\
\text { daughters/total } \\
\text { daughters }\end{array}$ \\
\hline Mother & $43 / 68$ & $33 / 55$ \\
Father & $12 / 21$ & $16 / 25$ \\
\hline
\end{tabular}

cording to the parent affected in Table 1. The data on the $\mathbf{N}$ family (presented below) are included.

\section{Case Report of $N$ Family}

DN was referred to the University of Michigan Medical Center at 17 years of age for a renal transplant. With the exception of neurosensory deafness that became clinically apparent at approximately 7 years of age, the patient was thought to be well until proteinuria was recognized during a routine physical examination at 14 years of age. A year later a more thorough evaluation demonstrated microhematuria and proteinuria in the nephrotic range. His creatinine clearance was $58 \mathrm{ml} / \mathrm{min} / 1.73 \mathrm{~m}^{2}$. An intravenous pyelogram was normal. Renal biopsy was attempted but was unsuccessful.

At approximately that time, an older male sibling who also had neurosensory deafness died of chronic renal failure. His mother's urinalysis showed no protein or blood. The father's urinalysis showed microhematuria. The patient's paternal grandmother was said to have kidney problems. One paternal uncle was alive and well at 51 and a paternal aunt had died at 32 with carbon monoxide poisoning. There was no known renal disease in the maternal line. A diagnosis of hereditary nephritis, Alport's type, was made.

During the 2 years prior to his admission to University Hospital, DN developed progressive renal failure and, at the time of his admission, his clearance was $2 \mathrm{ml} / \mathrm{min} / 1.73$ $\mathrm{m}^{2}$. He was hypertensive and anemic. Audiograms showed neurosensory deafness with losses up to 70 decibels in the range of 2,000 to 8,000 cycles per second.

Following bilateral nephrectomy, the patient received a kidney from his mother, since she was apparently unaffected. Multiple biopsies of the "donor kidney" had shown no evidence of pathology. The kidney functioned well, although an acute reversible rejection was sustained approximately 2 weeks following transplantation. The patient was discharged from the hospital and renal function remained good until the patient sustained an episode of acute pancreatitis followed by multiple medical and surgical complications that led to his death from pneumocystic pneumonia 16 months after transplantation.

Examination of the kidneys obtained at nephrectomy showed a right kidney of $39 \mathrm{~g}$ and a left kidney of $67 \mathrm{~g}$. The kidneys were finely granular, symmetrically contracted organs. On light microscopic examination, both kidneys were severely contracted with loss of both tubules and glomeruli. The remaining glomeruli manifested periglomerulofibrosis and extensive hyalinization within the tufts. Most tubules were atrophic. A few were hypoplastic and dilated. Dystrophic calcification was marked. Interstitial fibrous tissue appeared to be increased and it contained scattered chronic inflammatory cells. Both arterial and arteriolar sclerosis were present. Several cysts were present in renal papillae. Interstitial foam cells were not seen. It was considered that these were end-stage kidneys consistent with, but not diagnostic of, Alport's disease.

\section{Grand Rapids Pedigree}

There are now 308 persons documented as part of this extended family, 181 of whom were personally contacted. It was impossible to learn of the whereabouts and/or to obtain 


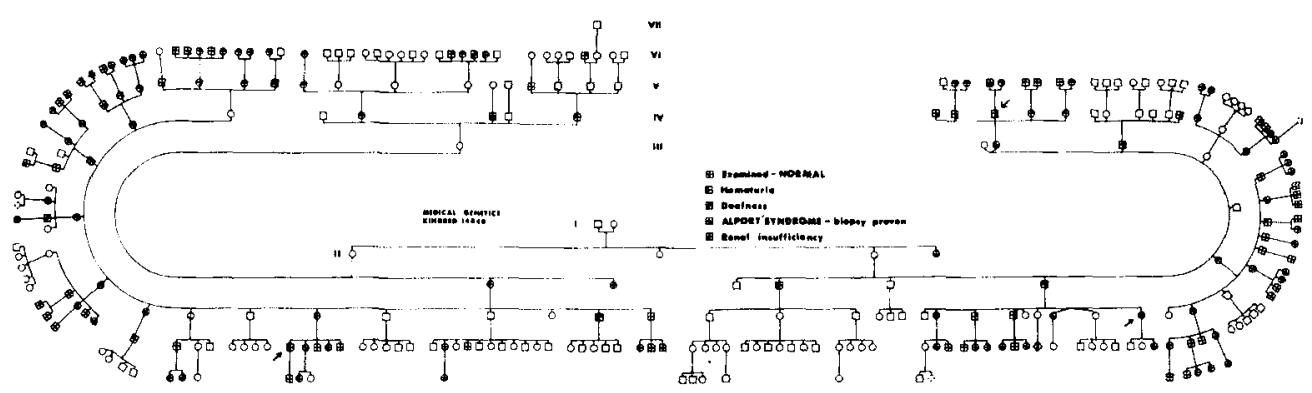

Fig. 1. Pedigree of Grand Rapids extended kindred of Alport's syndrome.

Key: upper left shaded - hematuria; upper right shaded - deafness; lower right shaded - biopsy proven Alport's; lower left shaded - renal insufficiency.

the cooperation of all those believed to be members of the pedigree, especially due to the death of affected fathers and the overall lack of communication in the family. The results of the urinalyses are shown in the pedigree (Fig. 1) and tabulated in Table 2. Several individuais not living at this time are considered to have been affected, on the basis of family and medical records, including autopsy reports when available.

Originally, there were thought to be at least two cases of male-to-male transmission of Alport's syndrome in the Grand Rapids pedigree. Investigation showed that one child is a female and the other died in infancy. His mother will not release his autopsy report. There are, however, two sons (IV-28, IV-29) of an affected father (III-7) who suffer from sensorineural deafness. The fact that they seem to be affected has not yet been supported by the presence

\section{Table 2}

Classification of individuals in Grand Rapids Alport's pedigree by sex, disease state, and affected parent

\begin{tabular}{|c|c|c|}
\hline $\begin{array}{l}\text { Affected } \\
\text { parent }\end{array}$ & $\begin{array}{c}\text { No. affected } \\
\text { sons/total sons }\end{array}$ & $\begin{array}{l}\text { No. affected } \\
\text { daughters/total } \\
\text { daughters }\end{array}$ \\
\hline Mother & $18 / 28$ & $17 / 32$ \\
\hline Father & $0 / 9$ & $7 / 10$ \\
\hline
\end{tabular}

of hematuria or affected offspring, and so these men can only be considered to be at most asymptomatic, and for tabulation purposes are considered normal. In two other instances (V-149, VI-61), the sons of affected fathers are still under the age of 10 , but on repeated urinalyses including the one on V-149 as part of this investigation, have shown occasional hematuria. The degree is slight and is not yet considered a definite indication of the disease, but the occurrence is worth noting. One boy $(\mathrm{V}-149)$ is also developing hearing problems, as yet of an unknown type. The pediatricians caring for both boys consider these findings insignificant.

It is interesting to note that in two of these three cases (III-7, V-31), in one other case in the pedigree (IV-3), and the case report of Family $\mathbf{N}$, the fathers are not severely affected with Alport's; none of them has shown any degree of renal insufficiency, and two (III-7, IV-3) have lived past the age of 60 . Deafness is present in both of the affected men in the Grand Rapids pedigree who have lived to be older than 60 years of age (III-7, IV-3).

\section{Discussion}

The fact that Alport's syndrome is inherited as a dominant has been well established 
Table 3

Comparison of transmission data from different sources

\begin{tabular}{|c|c|c|c|c|}
\hline \multirow[b]{2}{*}{ Source } & \multicolumn{2}{|c|}{ Mother affected } & \multicolumn{2}{|c|}{ Father affected } \\
\hline & AFF:NL & $\stackrel{q}{q}$ & $\begin{array}{c}\sigma \\
A F F: N L\end{array}$ & $\begin{array}{l}\stackrel{9}{+} \\
\mathrm{AFF}: \mathrm{NL}\end{array}$ \\
\hline Literature review (MacNeil \& Shaw 1973) & $244: 148$ & $286: 150$ & $71: 83$ & $130: 48$ \\
\hline $\begin{array}{l}\text { Literature review corrected for ascertainment bias } \\
\text { (Tishler \& Rosner 1974) }\end{array}$ & $98: 69$ & $109: 83$ & $10: 39$ & $37: 9$ \\
\hline Cases from children (Royer et al. 1974) & $26: 14$ & $17: 15$ & $0: 0$ & $2: 0$ \\
\hline Utah pedigree (O'Neill ot al. 1978) & $41: 53$ & $30: 50$ & $0: 22$ & $31: 5$ \\
\hline Grand Rapids pedigree (this study) & $18: 10$ & $17: 15$ & $0: 9$ & $7: 3$ \\
\hline$U$. of $M$. pedigrees (this study) & $43: 25$ & $33: 22$ & $12: 9$ & $16: 9$ \\
\hline
\end{tabular}

in the literature (Perkoff et al. 1951, Graham 1959, Shaw \& Glover 1961, Arnott et al. 1966, Purriel et al. 1970, Preus \& Fraser 1971, Iversen 1974, Shaw \& Kallen 1976, O'Neill et al. 1978) and is supported by the data presented here. For the most part, the disease occurs in every generation, and an affected individual has an affected parent. "Carriers" of Alport's syndrome (i.e., asymptomatic individuals shown to have the gene) occur with a relatively low frequency.

The question still remains as to the type of dominant inheritance this syndrome displays. Variation in the criteria used to detect Alport's syndrome in the past has led to both over- and underdiagnosis of the disease (Tishler \& Rosner 1974). Previously, almost any hereditary kidney disease was accepted as Alport's syndrome. The frequency of hereditary renal problems in the population is much too high, however, for this to be true. There is certainly more than one type of hereditary nephritis (Ben-Ishay et al. 1967, Teisberg et al. 1973) and Alport's syndrome should include only those families exhibiting sensorineural deafness with nephritis. With more sophisticated techniques for detecting hematuria and the increased sensitivity to its significance, the problem of underdiagnosis of individuals affected with Alport's (Shaw \& Glover 1961) has probably been reduced but not elimi- nated. Perhaps an even better method of detection of Alport's will be developed, helping to elucidate the mode of inheritance. Examination of Table 3 indicates the considerable variation in the data obtained by investigators of pedigrees of Alport's syndrome over the past 15 years. This variation, the source of which is unknown, is the basis for the different theories explaining the mode of inheritance of Alport's. In comparing these data sets, little is consistent except general trends. All sources except the University of Michigan pedigrees (row 6) indicate that an affected male will transmit the gene for Alport's syndrome to fewer than half of his sons (sometimes none) and to more than half of his daughters. Affected females transmit the gene to more than half of their children according to all data except the Utah pedigree (row 4).

The first theory to attempt to explain the mode of transmission was that of partial sex-linkage, proposed by Perkoff et al. (1951). Since then, this theory has been questioned and refuted on the grounds that statistical analyses of the data do not support a model of partial sex-linkage (Graham 1959, Shaw \& Glover 1961, Arnott et al. 1966, Preus \& Fraser 1971, Shaw \& Kallen 1976). Even stronger refutation is offered by the increasing cytological evidence against the possible occurrence of crossing- 
over between the $\mathrm{X}$ - and $\mathrm{Y}$-chromosomes. The homologous region of the sex chromosomes is on their short arms (Chen \& Falek 1969, Pearson \& Bobrow 1970), the arm of the Y-chromosome on which the genes determining maleness are believed to be located (Jacobs \& Ross 1966). Asynaptical pairing in this region seems likely in view of the fact that crossing-over would lead to too many abnormalities in the development of male sex characteristics.

As stated previously, one of the more recent theories (O'Neill et al. 1978) is that the Alport's gene is X-linked. The Utah and Grand Rapids pedigrees, rows 4 and 5 from Table 3, support this. In them, there is not a single case of male-to-male transmission; affected males pass the gene to nearly all of their daughters, affected females pass the gene to approximately half of their sons and half of their daughters. Unfortunately, because of their low fertility, there are few offspring of affected males to be considered (Shaw \& Glover 1961, Iversen 1974, Dzubia et al. 1975). Most males are so severely affected that they die in their early 20's. In the Grand Rapids pedigree, for example, 15 affected females had 48 children while 15 affected males had only 19 children. Twelve unaffected males had at least 28 children.

However, some pedigrees are obviously inconsistent with the theory of X-linkage. The most convincing one presented in this paper is the case of male-to-male transmission of the gene in Family N. There are also discrepancies in the Grand Rapids pedigree (Table 3, row 4, Fig. 1). First, there are not twice as many affected females as males; in fact, the ratio of affected males to affected females approaches 1:1 (Chi-square is less than 1). Secondly, $30 \%$ of the daughters of affected males are unaffected. While two of these girls (VI-40, V-150) are still fairly young and may develop hematuria later in life, one is older than her affected sister, yet remains unaffected, and the third female (Fig. 1, VI-26) is nearly 20 , by which time hematuria has usually developed in affected individuals (Shaw \& Glover 1961, Ferguson \& Rance 1972, Gaboardi et al. 1974, Hallberg 1976, Shaw \& Kallen 1976). Unaffected daughters of affected males occur in the Utah pedigree, too. O'Neill et al. (1978) propose the Lyon hypothesis to account for these cases, but the question remains as to what extent Lyonization could explain these unaffected females.

As seen in row 1 of Table 3, cases of male-to-male transmission of Alport's syndrome are repeatedly reported in the literature (Perkoff et al. 1951, Purriel et al. 1970, Preus \& Fraser 1971, Chavis \& Groshong 1973). It has been suggested (O'Neill et al. 1978) that were more sophisticated criteria used to review these pedigrees, all evidence of male-to-male transmission would be disproven. There are, however, several documented cases (Purriel et al. 1970, Preus \& Fraser 1971, Chavis \& Groshong 1973) in which both a man and his sons are considered affected using the criteria set forth in this paper. It is also true that individuals less severely affected with Alport's often have only intermittent hematuria (Shaw \& Glover 1961) and can therefore never be conclusively considered normal simply because red blood cells are not present in the urine. This becomes especially important if one of the males involved in the case of male-to-male transmission is likely to be very mildly affected (Purriel et al. 1970, Preus \& Fraser 1971, Chavis \& Groshong 1973, Hallberg 1976), as in the possible cases of male-to-male transmission in the Grand Rapids pedigree.

The only other possible type of dominant inheritance is autosomal. There are also many discrepancies with simple autosomal dominance, which dictates a $1: 1$ ratio of affected to unaffected individuals in both sexes. This implies an equal opportunity for a child of either sex to have inherited the 
disease from the parent of either sex. Such is not the case with Alport's syndrome. There are far fewer cases of a male inheriting the gene from his father than from his mother (Shaw \& Glover 1961, Purriel et al. 1970, Iversen 1974, Dzubia et al. 1975, Shaw \& Kallen 1976). Many modifications have been proposed to explain this phenomenon, but none has been conclusively proven. Intrauterine death of male fetuses due to extremely severe disease (Graham 1959, Arnott et al. 1966), or unfavorable intrauterine milieu (Purriel et al. 1970, Preus \& Fraser 1971, Shaw \& Kallen 1976), or rejection of the fetus by a normal mother, seem plausible suggestions, but as of yet there has been no documentation of these alleged fetal deaths. Of the 552 children born to the affected males reviewed in this paper (see Table 2, columns 3 and 4) 297 are female and 255 are male. These nearly equal numbers of children of each sex (Chisquare $=1.45, P>0.05$ ) tend to disprove the theory of fetal deaths of affected sons of affected males. In that case, the number of daughters would be expected to be twice that of living sons (Chi-square $=18.53$, $P<<0.01$ ). In the Grand Rapids pedigree (Fig. 1), unaffected mothers of affected children did not report an unusual number of spontaneous abortions or unexplained miscarriages. Extremely variable expression of the disease in males has also been proposed, emphasizing the fact that an affected mother will have much more severely affected sons than an unaffected mother, due to the unfavorable uterine milieu (Shaw \& Glover 1961, Purriel et al. 1970, Preus \& Fraser 1971, Hallberg 1976, Shaw \& Kallen 1976). This would indicate an equal number of carriers of asymptomatic males and symptomatic males, and such is not the case. For example, only four potentially asymptomatic males occur in the Grand Rapids pedigree as opposed to 18 affected males. Fewer carriers are reported now than in the past, probably due to the fact that hematuria is more frequently sought and detected, indicating affected individuals. Male carriers are very rare indeed.

Abnormal chromosomal disjunction is another possible explanation of the observed deviations from Mendelian inheritance patterns. In one postulated mechanism, the gene for Alport's syndrome would be on an autosome that associates with the X-chromosome during male, but not female, meiosis while segregation distortion would occur in oogenesis (Cohen et al. 1961, Shaw \& Glover 1961). This theory would explain the fact that some affected females have more than $50 \%$ affected offspring (Table 3 , columns 1 and 2) as well as the excess of affected female and deficiency of affected male offspring of affected males (Table 3, columns 3 and 4). The fact that segregation ratios differ from one source to another could indicate genetic heterogeneity, as has been suggested by Tishler \& Rosher (1974) on the basis of two classes of pedigrees separated on the age of death of affecteds. Alternatively, some of the variation could result from different criteria used in diagnosis of patients (Preus \& Fraser 1971).

The question remains as to why this variation exists. Error in detection methods including underdiagnosis does not seem to be the only source of variation, especially in light of the cases of male-to-male transmission in this and other papers (Purriel et al. 1970, Preus \& Fraser 1971, Chavis \& Groshong 1973). Even the two pedigrees in which almost identical criteria were used to determine the status of an individual with respect to Alport's syndrome (Table 3, rows 4 and 5) do not offer mutually supportive data. It seems highly possible that there is heterogeneity in the inheritance pattern of this trait, a fact which would perhaps explain the variable severity of the disease. The mode of transmission must be consistent within a given family, although oc- 
casionally there is variation between sibships in large families in the severity with which individuals are affected with Alport's (Ferguson \& Rance 1972).

\section{Acknowledgments}

We wish to thank Mrs. Grace Sundling for drawing the pedigree and Mrs. Rena Jones for typing the manuscript.

\section{References}

Alport, A. C. (1927). Hereditary familial congenital haemorrhagic nephritis. Brit. med. J. 1, 504-506.

Arnott, E. J., M. d'A. Crawfurd \& P. J. Tognill (1966). Anterior lenticonus and Alport's syndrome. Brit. J. Ophthal. 50, 390-403.

Ben-Ishay, D., S. Biran \& T. D. Ullmann (1967). Familial nephritis. Israel J. med. Sci. 3, 106112.

Chavis, R. M. \& T. Groshong (1973). Corneal arcus in Alport's syndrome. Amer. $J$. Ophthal. 75, 793-794.

Chen, A. T. L. \& A. Falek (1969). Centromeres in human meiotic chromosomes. Science 166, 1008-1010.

Cohen, M. M., G. Cassady \& B. L. Hanna (1961). A genetic study of hereditary renal dysfunction with associated nerve deafness. Amer. J. hum. Genet. 13, 379-389.

Dzubia, P., A. Kobierska-Szczepanska \& K. Jonczyk (1975). Genetical investigations of familial nephropathy. Gen. Pol. 16, 229-233.

Ferguson, A. C. \& C. P. Rance (1972). Hereditary nephropathy with nerve deafness (Alport's syndrome). Amer. J. Dis. Child. 124, 83-88.

Gaboardi, F., A. Edefonti, E. Imbasciata, A. Tarantino, M. J. Mihatsch \& H. U. Zollinger (1974). Alport's syndrome (progressive hereditary nephritis). Clin. Neph. 2, 143-156.

Graham, J. B. (1959). Hereditary chronic kidney disease: An alternative to partial sex-linkage in the Utah kindred. Amer. J. hum. Genet. 11, 333-338.

Hallberg, A. (1976). Alport's syndrome. Acta paediat. scand. 65, 49-56.

Iversen, U. M. (1974). Hereditary nephropathy with hearing loss "Alport's syndrome". Acta paediat. scand. Suppl. 245, 5-23.

Jacobs, P. A. \& A. Ross (1966). Structural abnormalities of the $Y$-chromosome in man. Nature 210, 352-354.

MacNeill, E. \& R. F. Shaw (1973). Segregation ratios in Alport's syndrome. J. med. Genet. 10, 23-26.

O'Neill, W. M., C. L. Atkin \& H. A. Bloomer (1978). Hereditary nephritis. A re-examination of its clinical and genetic features. $A n n$. int. Med. 88, 176-182.

Pearson, P. L. \& M. Bobrow (1970). Definitive evidence for the short arm of the Y-chromosome associating with the X-chromosome during meiosis in the human male. Nature 226, 959-961.

Perkoff, G. T., F. E. Stephens, D. A. Dolowitz \& F. H. Tyler (1951), A clinical study of hereditary interstitial pyelonephritis. $A M A$ Arch. int. Med. 88, 191-200.

Preus, M. \& F. C. Fraser (1971). Genetics of hereditary nephropathy with deafness (Alport's disease). Clin. Genet. 2, 331-337.

Purriel, P., M. Drets, E. Pascale, R. S. Cestau, A. Borras, W. A. Ferreira, A. De Lucca \& L. Fernandez (1970). Familial hereditary nephropathy (Alport's syndrome). Amer. J. Med. 49, 753-773.

Royer, P., R. Habib, H. Mathieu \& M. Broyer (1974). Pediatric Nephrology. Philadelphia, W. B. Saunders, pp. 37-42.

Shaw, R. F. \& R. A. Glover (1961). Abnormal segregation in hereditary renal disease with deafness. Amer. J. hum. Genet. 13, 89-97.

Shaw, F. F. \& R. J. Kallen (1976). Population genetics of Alport's syndrome. Nephron 16, 427-432.

Teisberg, P., K. A. Gröttum, E. Myhre \& A. Flatmark (1973). In vivo activation of complement in hereditary nephropathy. Lancet ii, 356-358.

Tishler, P. V. \& B. Rosner (1974). The genetics of the Alport syndrome. Birth Defects 10, 93-99.

\section{Address:}

Robert P. Erickson, M.D.

Department of Human Genetics

University of Michigan School of Medicine

Ann Arbor, Michigan 48109

U.S.A. 